\title{
DANOS MECÂNICOS ASSOCIADOS A PATÓGENOS E DESEMPENHO DE SEMENTES DE MILHO ${ }^{(1)}$
}

\author{
CARLOS MOURE CICERO ${ }^{(2)}$; WALTER RODRIGUES DA SILVA ${ }^{(3)}$
}

\begin{abstract}
RESUMO
As danificações provocadas nas sementes por operações mecanizadas realizadas durante a produção podem atuar negativamente na qualidade do material obtido. Essa redução qualitativa, segundo a literatura específica, pode ser agravada quando a injúria interage com microrganismos presentes na superfície das sementes ou no solo, por ocasião da semeadura. Dessa forma, o presente trabalho, realizando inoculações de patógenos e injúrias nas regiões da calota endospermática, do ápice do escutelo e da camada negra em sementes de milho (Zea mays L.), objetivou verificar as relações existentes entre as danificações mecânicas, a presença de microrganismos e o desempenho das sementes. Após a realização de testes sanitários e fisiológicos, concluiu-se que as danificações, particularmente quando Aspergillus sp. e Fusarium moniliforme se encontram presentes nas sementes, promovem prejuízos qualitativos progressivos à medida que se aproximam do embrião. Quando comparadas entre si, as interferências negativas de Aspergillus sp. e de F. moniliforme são mais evidentes do que as de Penicillium sp.
\end{abstract}

Palavras-chave: sanidade, fungos, germinação, vigor.

\section{ABSTRACT \\ MECHANICAL DAMAGES ASSOCIATED WITH PATHOGENS AND PERFORMANCE OF CORN SEEDS (Zea mays L.)}

The damages caused to seeds due to mechanized operations performed along the production process can negatively affect the quality of the material obtained. According to specific literature, this qualitative reduction can be aggravated when the injury interacts with the microorganisms found in the seed surface or in the soil at seeding. Thus, by performing pathogen inoculations and injuries in the region of the endosperm cap, top of scutellum and black layer of corn seeds, the aim of this paper was to verify the existing relationship between the mechanical damages, the presence of microorganisms and seed performance. After sanitary and physiological tests were carried out it was concluded that the damages, particularly when Aspergillus sp. and Fusarium moniliforme were found in the seeds, promote progressive qualitative losses as they approach the embryo. When compared with one another the negative interferences of Aspergillus sp. and F. moniliforme are more evident than those of the Penicillium sp.

Key words: seed pathology, fungi, germination, vigor.

$\left({ }^{1}\right)$ Parte da Dissertação de Mestrado do primeiro autor apresentada à USP/ESALQ - Piracicaba (SP). Recebido para publicação em 15 de outubro de 2002 e aceito em 24 de outubro de 2003.

$\left(^{2}\right)$ Universidade de Taubaté, Rua 4 de março, 420, 12100-000 Taubaté (SP). E-mail: cmcicero@ig.com.br.

$\left({ }^{3}\right)$ Departamento de Produção Vegetal, Escola Superior de Agricultura “Luiz de Queiróz" (USP), Caixa Postal 9, 13418-900 Piracicaba (SP). E-mail: wrsilva@carpa.ciagri.usp.br 


\section{INTRODUÇÃO}

A necessidade de redução das danificações mecânicas, surgidas nas etapas de produção das sementes de milho, tem justificado a adoção de tecnologias especificamente voltadas a essa finalidade. Contudo, apesar da possível moderação em número e intensidade, as injúrias não podem ser totalmente evitadas em decorrência do uso imprescindível de máquinas, particularmente durante a debulha e o beneficiamento.

Assim, a debulha, o processamento e o armazenamento têm recebido recomendações voltadas à redução das injúrias (Pollock e Roos, 1972; Popinigis, 1977; Carvalho e NaKagawa, 1983). Segundo Finch et al. (1980), as espigas de milho devem ser colhidas com teor de água das sementes entre $20 \%$ e $25 \%$, secas até $15 \%$ a $18 \%$ para, em seguida, serem debulhadas. Por outro lado, GonçALVES (1981) concluiu que os métodos de colheita com debulha associada não se mostraram inferiores aos com debulha isolada, concordando com CraIG (1977) ao recomendar colheita e debulha conjuntas. SATO (1974) observou que as sementes provenientes de colheita com debulha realizada mecanicamente no campo apresentaram maior incidência de danos mecânicos. Entretanto, quando a colheita em espigas foi realizada sem seleção posterior, não se observaram diferenças na germinação das sementes provenientes dos diferentes métodos de debulha.

As danificações mecânicas não suficientes para destruir as estruturas essenciais das sementes (danos não visíveis) proporcionam aumento no número de plântulas anormais, maior suscetibilidade à ação dos microrganismos, maior sensibilidade aos tratamentos químicos e diminuição do potencial de armazenamento, principalmente, em safras transcorridas sob condições ambientais desfavoráveis na maturação e na colheita (BEWLEY e BLACK, 1985).

Além disso, os efeitos cumulativos das danificações mecânicas afetam negativamente a germinação, o vigor e o potencial de produtividade das sementes (COPELAND, 1972; FAGUNDES, 1985; CARVALHO E NAKAGAWA, 1983).

O efeito gerado ganha importância em virtude da abertura de canais para a entrada de microrganismos patogênicos (SOAVE e WETZEL, 1987) e é agravado, paralelamente, quando as injúrias se aproximam do embrião (WORTMAN e RINKE, 1951; CARVAlho e NaKagawa, 1983). Danos aplicados ao endosperma córneo das sementes de milho, não causaram redução no desempenho (KoeHLER, 1935; WortMan e RinKe, 1951; MCKeEN e Macdonald, 1976; SILVA et al. 1994).
Dessa maneira, o conhecimento estabelecido mostra a importância da interferência do dano mecânico no desempenho das sementes, particularmente em virtude de sua associação com o estabelecimento de microrganismos. Assim, o objetivo do presente trabalho foi estudar, em sementes de milho, as relações existentes entre os danos mecânicos, a presença de microrganismos e o desempenho fisiológico.

\section{MATERIAL E MÉTODOS}

As sementes de milho híbrido da cultivar AG 352 foram colhidas manualmente "em espiga" e secas em equipamento estacionário. A debulha, limpeza e classificação foram realizadas em equipamentos de acionamento manual, a fim de diminuir a ocorrência de danos mecânicos. O lote experimental constitui-se de sementes puras que, retidas na peneira com crivos circulares de 22/64 de polegada, representaram a maior fração da população classificada em peneiras dispostas em ordem decrescente, com crivos circulares de diâmetro variando em 1/64 de polegada, no intervalo de 25/64 a 18/64 de polegada.

Em seguida à classificação, as sementes foram danificadas, através do uso de bisturi equipado com limitador de ação, com cortes de $1 \mathrm{~mm}$ de comprimento e $2 \mathrm{~mm}$ de profundidade. Dessa maneira, sem que os eixos embrionários fossem atingidos, foram obtidas sementes intactas (Do) e danificadas nas regiões da calota endospermática $\left(D_{1}\right)$, do ápice do escutelo $\left(D_{2}\right)$ e da camada negra $\left(D_{3}\right)$, conforme as indicações da figura 1.

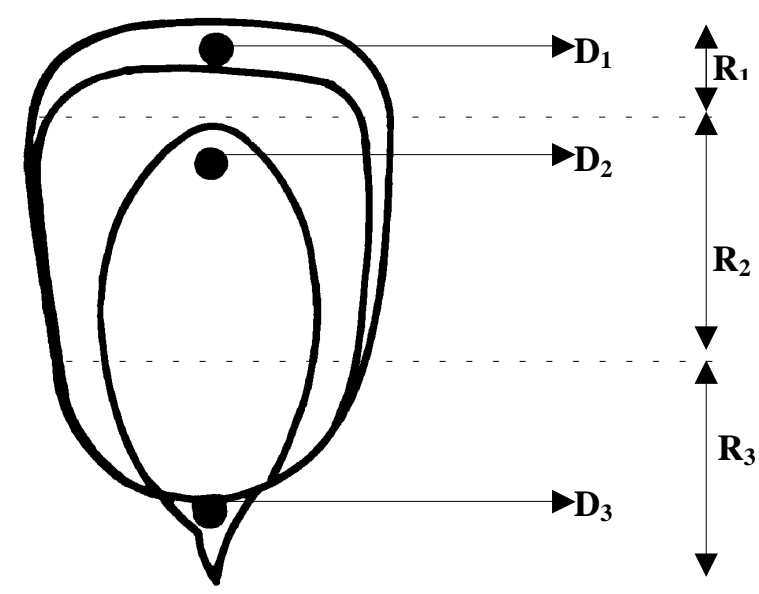

Figura 1. Localizações dos danos $D_{1}$ (calota endospermática), $\mathrm{D}_{2}$ (ápice do escutelo) e $\mathrm{D}_{3}$ (camada negra), provocados nas sementes e respectivas regiões $\left(R_{1}, R_{2}\right.$ e $\left.R_{3}\right)$ consideradas na determinação da densidade ponderada de infecção. 
Posteriormente, as sementes foram submetidas aos seguintes procedimentos, denominados etapas de inoculação:

a) Assepsia: as sementes foram desinfetadas superficialmente com hipoclorito de sódio (1\%) por 3 minutos e lavadas com água destilada; após isso, foram colocadas para secar à sombra por um período de 24 horas.

b) Assepsia + BDA: após a desinfecção superficial, as sementes foram agitadas em placas de Petri, contendo meio de cultura BDA (200 g de batata, $15 \mathrm{~g}$ de ágar, $20 \mathrm{~g}$ de dextrose e $1.000 \mathrm{~mL}$ de água destilada), e em seguida, colocadas para secar à sombra durante 24 horas.

c) Assepsia + BDA + Fungo: primeiramente, foi obtida a cultura pura de cada fungo, em tubos de ensaio, com posterior repicagem para placas de Petri, contendo meio de cultura BDA. Foram utilizados como inóculo os fungos: Aspergillus sp., Penicillium sp. e Fusarium moniliforme, individualmente. Após seu desenvolvimento no meio de cultura, as sementes foram submetidas à inoculação, pelo método de contato: sementes desinfetadas foram transferidas para as placas, contendo colônias dos fungos e agitadas para que os conídios recobrissem sua superfície. Posteriormente, foi realizada secagem à sombra durante 24 horas.

Assim, cada uma das fontes de inóculo constituiu um experimento isolado que abrigou os tratamentos representados pelos danos mecânicos $\left(D_{0}\right.$, $\mathrm{D}_{1}, \mathrm{D}_{2}$ e $\mathrm{D}_{3}$ ) e pelas etapas de inoculação (Assepsia, Assepsia + BDA e Assepsia + BDA + fungo) de cada fungo.

\subsection{Determinações}

a) Grau de umidade: utilizou-se o método de estufa, a $105 \pm 3{ }^{\circ} \mathrm{C}$ durante 24 horas, empregando duas amostras por repetição, conforme as indicações das Regras para Análise de Sementes (BrAsIL, 1992). Os resultados foram expressos em porcentagem na base úmida.

b) Teste de dano mecânico: empregou-se o teste da tintura de iodo. Duas amostras de 100 sementes por repetição foram colocadas em copos plásticos, adicionando-se tintura de iodo (solução a $4 \%$ ) em quantidade suficiente para cobrir as sementes e, após cinco minutos de imersão, foram lavadas. Considerouse como danificadas as sementes que apresentaram sinais de cor roxa, provenientes da reação entre o iodo e o amido. Os resultados foram expressos em porcentagem, segundo as recomendações de MARCos FILHO et al. (1987). c) Teste de sanidade: aplicou-se o teste do papel- filtro: avaliaram-se 50 sementes por repetição. As sementes foram distribuídas em placas de Petri, contendo três folhas de papel- filtro previamente embebidas em água destilada. As sementes foram incubadas no interior de estufa mantida a $20 \pm 2{ }^{\circ} \mathrm{C}$, por um dia, com alternância de luz e escuro de 12 horas. A seguir, foram retiradas e colocadas em congelador por 24 horas, sendo depois retornadas à incubação no interior da estufa durante sete dias. Após esse período, foram avaliadas as incidências de fungos dos gêneros Aspergillus, Penicillium e Fusarium nas sementes, com auxílio de microscópio estereoscópico e composto.

d) Estimativa da densidade ponderada de infecção (DPI): realizada durante a interpretação do teste de sanidade, considerou, exclusivamente, as sementes incubadas com os diferentes fungos (Assepsia + BDA + Fungo) e as regiões $R_{1}, R_{2}$ e $R_{3}$ (Figura 1) da superfície das sementes que abrigavam, respectivamente, os locais de aplicação dos danos $\mathrm{D}_{1}, \mathrm{D}_{2}$ e $\mathrm{D}_{3}$. A ocorrência de patógenos, estimada através de notas $(0,1$ e 2$)$, segundo a área ocupada, foi representada, por região, pela média das notas atribuídas aos indivíduos. Aplicou-se a equação desenvolvida por Mckinney, para o cálculo do índice de doenças em plantas, adaptada por MACHADO e Martins (1999) para a estimativa da densidade ponderada de infecção em sementes:

$$
\mathrm{DPI}=\frac{\left(\mathrm{f}_{0} \times \mathrm{n}_{0}\right)+\left(\mathrm{f}_{1} \times \mathrm{n}_{1}\right)+\left(\mathrm{f}_{2} \times \mathrm{n}_{2}\right)}{\mathrm{F} \times \mathrm{N}} \times 100, \text { em que: }
$$

$\mathrm{f}_{0}, \mathrm{f}_{1}$ e $\mathrm{f}_{2}=$ número respectivo de indivíduos em cada uma das notas. região).

$$
\mathrm{n}_{0}=0 \text { (nota para ausência de fungos na }
$$

$\mathrm{n}_{1}=1$ (nota para 1 a $40 \%$ da região ocupada por fungos).

$\mathrm{n}_{2}=2$ (nota para 41 a $100 \%$ da região ocupada por fungos).

$\mathrm{F}=200$ (número total de indivíduos).

$\mathrm{N}=2$ (nota máxima atribuível).

e) Teste de germinação: foi realizado com 100 sementes, por repetição, instaladas em rolo de papeltoalha sob $25^{\circ} \mathrm{C}$. A massa de água utilizada para embebição foi o equivalente a 2,5 vezes a do substrato seco. As contagens foram realizadas aos quatro e sete dias após a semeadura e, a avaliação, efetuada segundo os critérios estabelecidos pelas Regras de Análise de Sementes (BrasiL, 1992), computou a freqüência de plântulas normais. 
f) Teste de frio: foi realizado utilizando-se substrato resultante da mistura de $1 / 3$ de terra (proveniente de área cultivada com milho) e $2 / 3$ de areia, colocada em caixa plástica. Após a semeadura de 50 sementes por repetição, procedeu-se a irrigação até que fosse atingida $60 \%$ da capacidade de retenção de água na mistura. Os recipientes foram mantidos tampados e colocados em câmara a $10{ }^{\circ} \mathrm{C}$ durante sete dias, conforme o recomendado por MARCos FILHO et al. (1987). Após esse período, foram retirados e colocados em ambiente não controlado, onde permaneceram por sete dias para a contagem e cálculo percentual das plântulas emersas.

g) Teste de comprimento da plântula: foi feito em rolo de papel umedecido como o descrito para o teste de germinação, empregando três amostras de 10 sementes por repetição. A semeadura foi efetuada sobre uma linha horizontal traçada no terço superior do papel em direção longitudinal, ou seja, no sentido do maior comprimento da folha. Os rolos, embalados em sacos plásticos e dispostos verticalmente em germinador (KRZYANOWSKI et al., 1991), foram mantidos por quatro dias sob temperatura de $25{ }^{\circ} \mathrm{C}$. Decorrido esse período, todos os indivíduos foram avaliados individualmente e medidos com régua, com subdivisões em milímetro. O comprimento médio da plântula foi obtido pelo quociente entre a soma das medidas tomadas e o número total de indivíduos instalados em cada amostra.

h) Teste de emergência das plântulas: foram utilizadas 50 sementes por repetição, em campo manti- do sob irrigação, em linhas de 2,0 m espaçadas de 0,3 $\mathrm{m}$ entre si. A avaliação foi realizada aos 21 dias após a semeadura, computando-se a porcentagem de plântulas emersas em método semelhante ao descrito por NAKAgAWA (1994).

Empregou-se o delineamento inteiramente casualizado em esquema fatorial com quatro repetições. Os dados obtidos na avaliação dos tratamentos, pelos testes fisiológicos (germinação, frio, comprimento de plântula e emergência das plântulas) e pelo teste de densidade ponderada de infecção, foram submetidos à análise estatística, isoladamente por experimento, e tiveram as médias comparadas pelo teste de Tukey (5\%). Foi utilizado o Sistema de Análise Estatística - SANEST (ZONTA e MACHADO, 1984).

\section{RESULTADOS E DISCUSSÃO}

Os graus de umidade (Quadro 1) apresentaram uniformidade suficiente para sugerir ausência de efeitos dos tratamentos nessa variável e, portanto, reduzida interferência da umidade nas demais determinações realizadas, particularmente as destinadas à avaliação do desempenho fisiológico das sementes. As danificações realizadas, ausentes em $\mathrm{D}_{0}$, foram invariavelmente verificadas em todas as sementes pertencentes aos tratamentos $D_{1}, D_{2}$ e $D_{3}$ no teste de dano mecânico e, dessa forma, ficou atestada a existência das injúrias-objeto do estudo.

Quadro 1. Grau de umidade (\%) de sementes de milho submetidas a diferentes tipos de danificação mecânica e de inoculação

\begin{tabular}{clcccr}
\hline \multirow{2}{*}{ Experimento } & \multirow{3}{c}{ Danificação } \\
\cline { 3 - 5 } & Etapa de inoculação & $\mathrm{D}_{0}$ & $\mathrm{D}_{1}$ & $\mathrm{D}_{2}$ & $\mathrm{D}_{3}$ \\
\hline \multirow{3}{*}{1} & Assepsia & 12,4 & 12,6 & 12,2 & 12,4 \\
& Assepsia + BDA & 12,0 & 12,5 & 12,3 & 12,2 \\
& Assepsia + BDA + Aspergillus sp. & 12,3 & 12,3 & 12,2 & 12,2 \\
& Assepsia & 12,5 & 12,4 & 12,4 & 12,3 \\
2 & Assepsia + BDA & 11,9 & 12,4 & 12,5 & 12,2 \\
& Assepsia + BDA + Penicillium sp. & 12,2 & 12,2 & 12,4 & 12,1 \\
& Assepsia & 12,4 & 12,4 & 12,4 & 12,2 \\
& Assepsia + BDA & 12,4 & 12,6 & 12,4 & 12,2 \\
& Assepsia + BDA + Fusarium moniliforme & 12,6 & 12,5 & 12,2 & 12,2 \\
\hline
\end{tabular}

BDA: meio de cultura. 
O teste de sanidade (Quadro 2) detectou incidências de $100 \%$ para todos os fungos inoculados nos respectivos experimentos; contudo, verificou que a assepsia realizada não erradicou o $F$. moniliforme, pois apesar de não apresentar incidências superiores a 11,5\% em Assepsia e Assepsia + BDA, manteve-se presente em todos os experimentos. A densidade ponderada de infecção (Quadro 3), estimando a colonização de microrganismos nas sementes, mostrou, na ausência de dano $\left(D_{0}\right)$ em todos os experimentos, a ampliação de valores no sentido da região da calota endospermática $\left(R_{1}\right)$ para a da camada negra $\left(R_{3}\right)$.

Consideradas, isoladamente, as danificações $D_{1}, D_{2}$ e $D_{3}$ no experimento 3 (com inoculação de F. moniliforme), as maiores áreas colonizadas ocorreram, respectivamente, nas regiões $R_{1}, R_{2}$ e $R_{3}$ que correspondiam às de realização dos danos; no experimento 1 (Aspergillus sp.), essa ocorrência esteve presente em $\mathrm{D}_{2}$ e $\mathrm{D}_{3}$ e ausente em $\mathrm{D}_{1}$.

No experimento 2 (Penicillium sp.), os dados não evidenciaram relações diretas entre o local de realização do dano e a superfície colonizada pelos patógenos e, da mesma forma que o verificado em $\mathrm{D}_{0}$ em todos os experimentos, destacaram a ocorrência de maiores áreas colonizadas nas regiões próximas ao embrião $\left(R_{2}\right.$ e $\left.R_{3}\right)$ do que na da calota endospermática $\left(R_{1}\right)$. Assim, os dados relativos ao quadro 3, particularmente para Aspergillus sp. e para F. moniliforme, mostraram que o local da danificação favorece o estabelecimento dos microrganismos que, nas sementes intactas, concentra-se na região da ligação das sementes com o sabugo (camada negra).

$\mathrm{Na}$ observação dos dados de germinação (Quadro 4), dentro das etapas de inoculação, verifica-se predominância da inferioridade de $\mathrm{D}_{2}$ e $\mathrm{D}_{3}$, em relação a $\mathrm{D}_{0}$ e $\mathrm{D}_{1}$, particularmente nos procedimentos que incluíram os fungos; excetuando-se a superioridade de $D_{0}$ em relação a $D_{1}$, observada na presença de F. moniliforme, as duas danificações apresentaram comportamento semelhante entre si nos demais casos. Fixadas as danificações, houve indicação de tendência de redução nos valores de Assepsia + BDA + fungos em relação à Assepsia. Tal efeito, em comparação dentro das danificações $\mathrm{D}_{1}, \mathrm{D}_{2}$ e $\mathrm{D}_{3}$, deixou de ocorrer, exclusivamente, com Penicillium sp em $\mathrm{D}_{1}$; nas sementes não danificadas $\left(\mathrm{D}_{0}\right)$, contudo, observou-se unicamente no experimento infectado com F. moniliforme. Assim, levando em conta as informações existentes no quadro 4, a germinação foi negativamente influenciada, especialmente, quando os danos $D_{2}$ e $D_{3}$ estiveram associados às inoculações com os fungos.

Os dados do teste de frio (Quadro 5), excetuando-se os da danificação $\mathrm{D}_{1}$ em Assepsia + BDA +
Penicillium sp., detectaram efeitos fisiológicos negativos das danificações $D_{1}, D_{2}$ e $D_{3}$ nas comparações com $\mathrm{D}_{0}$, independentemente da etapa de inoculação considerada. Entre as etapas de inoculação, as de Assepsia + BDA + fungos, excetuando-se a de Penicillium sp. em $\mathrm{D}_{1}$ e $\mathrm{D}_{3}$ e as demais em $\mathrm{D}_{1}$, geraram prejuízos quando comparadas com a Assepsia. Dessa forma, o teste de frio detectou evidências da soma de prejuízos qualitativos das danificações $\mathrm{D}_{2} \mathrm{e}$ $\mathrm{D}_{3}$ com as etapas de inoculação que continham os fungos.

O teste de comprimento da plântula (Quadro 6), dentro de todas as etapas de inoculação, indicou inferioridades de $\mathrm{D}_{2}$ e de $\mathrm{D}_{3}$ nas comparações com $\mathrm{D}_{0}$ e com $\mathrm{D}_{1}$.

Adicionalmente, as etapas de Assepsia + BDA + fungos geraram decréscimos qualitativos, em relação à Assepsia, dentro de todas as danificações. Dessa maneira, os dados obtidos sugeriram que a redução qualitativa provocada pelas inoculações dos fungos, apesar de ocorrer nas sementes intactas $\left(D_{0}\right)$, foi ampliada na presença das injúrias $D_{2}$ e $D_{3}$ que, independentemente das etapas de inoculação, mostraram-se capazes de gerar prejuízos fisiológicos.

No teste de emergência das plântulas (Quadro 7), os danos $\mathrm{D}_{2}$ e $\mathrm{D}_{3}$, em todas as etapas de inoculação, reduziram a qualidade fisiológica nas comparações com $\mathrm{D}_{0}$, em tendência similar às verificadas nos testes de germinação (Quadro 4), de frio (Quadro 5) e de comprimento da plântula (Quadro 6). Dentro das danificações, com exceção feita à Assepsia + BDA + Aspergillus sp. em $\mathrm{D}_{0}$, as etapas de Assepsia + BDA + fungos trouxeram prejuízos nos confrontos com Assepsia, em $D_{0}, D_{1}$ e $D_{2}$, e não mostraram os efeitos negativos verificados nos demais testes fisiológicos em $D_{3}$.

Assim, considerando o conjunto dos dados provenientes dos testes realizados, foram possíveis as seguintes observações. Os danos mecânicos, isoladamente, reduziram a qualidade fisiológica das sementes em intensidade variável e dependente das suas localizações.

Sob esse aspecto, os aplicados no ápice do escutelo $\left(D_{2}\right)$ e na região da camada negra $\left(D_{3}\right)$ foram mais prejudiciais do que o realizado na calota endospermática $\left(\mathrm{D}_{1}\right)$, com localização mais distante do embrião. Essa constatação, relacionando a gravidade do dano com a proximidade ao embrião, foi similarmente referida por WORTMAN e RINKE (1951) e Carvalho e Nakagawa (1983). Por outro lado, pesquisas realizadas por Koelher (1935), McKeen E MACDonAld (1976) e Silva et al. (1994), que aplicaram danos controlados e dirigidos ao endosperma córneo das sementes de milho, não constataram prejuízos relacionados ao desempenho. 
Quadro 2. Incidência (\%) de fungos em sementes de milho, submetidas a diferentes tipos de danificação mecânica e de inoculação

\begin{tabular}{|c|c|c|c|c|c|c|}
\hline \multirow{2}{*}{ Experimento } & \multirow{2}{*}{ Etapa de inoculação } & \multirow{2}{*}{ Fungo } & \multicolumn{4}{|c|}{ Danificação } \\
\hline & & & $\mathrm{D}_{0}$ & $\mathrm{D}_{1}$ & $\mathrm{D}_{2}$ & $\mathrm{D}_{3}$ \\
\hline & Assepsia & Aspergillus spp. & 0,0 & 0,0 & 0,0 & 0,0 \\
\hline & & Penicillium spp. & 0,0 & 0,0 & 0,0 & 0,0 \\
\hline & & Fusarium moniliforme & 10,0 & 7,0 & 6,0 & 7,0 \\
\hline \multirow[t]{9}{*}{1} & Assepsia + BDA & Aspergillus spp. & 0,0 & 0,0 & 0,0 & 0,0 \\
\hline & & Penicillium spp. & 0,0 & 0,0 & 0,0 & 0,0 \\
\hline & & Fusarium moniliforme & 2,5 & 6,0 & 11,0 & 11,5 \\
\hline & Assepsia + BDA + Aspergillus sp. & Aspergillus spp. & 100 & 100 & 100 & 100 \\
\hline & & Penicillium spp. & 0,5 & 0,0 & 0,0 & 0,0 \\
\hline & & Fusarium moniliforme & 1,5 & 1,5 & 1,5 & 2,5 \\
\hline & Assepsia & Aspergillus spp. & 0,0 & 0,0 & 0,0 & 0,0 \\
\hline & & Penicillium spp. & 0,0 & 0,0 & 0,0 & 0,0 \\
\hline & & Fusarium moniliforme & 1,5 & 4,0 & 10,0 & 10,5 \\
\hline \multirow[t]{9}{*}{2} & Assepsia $+B D A$ & Aspergillus spp. & 0,0 & 0,0 & 0,0 & 0,0 \\
\hline & & Penicillium spp. & 0,0 & 0,0 & 0,0 & 0,0 \\
\hline & & Fusarium moniliforme & 2,0 & 4,0 & 9,0 & 10,5 \\
\hline & Assepsia $+B D A+$ Penicillium sp. & Aspergillus spp. & 0,0 & 0,0 & 0,0 & 0,0 \\
\hline & & Penicillium spp. & 100 & 0,0 & 0,0 & 0,0 \\
\hline & & Fusarium moniliforme & 2,5 & 4,0 & 9,0 & 11,5 \\
\hline & Assepsia & Aspergillus spp. & 0,0 & 0,0 & 0,0 & 0,0 \\
\hline & & Penicillium spp. & 0,0 & 0,0 & 0,0 & 0,0 \\
\hline & & Fusarium moniliforme & 2,0 & 5,5 & 9,0 & 11,0 \\
\hline \multirow[t]{6}{*}{3} & Assepsia + BDA & Aspergillus spp. & 0,0 & 0,0 & 0,0 & 0,0 \\
\hline & & Penicillium spp. & 0,0 & 0,0 & 0,0 & 0,0 \\
\hline & & Fusarium moniliforme & 3,0 & 5,0 & 10,0 & 10,0 \\
\hline & Assepsia + BDA + F.moniliforme & Aspergillus spp. & 0,0 & 0,0 & 0,0 & 0,0 \\
\hline & & Penicillium spp. & 0,0 & 0,0 & 0,0 & 0,0 \\
\hline & & Fusarium moniliforme & 100 & 100 & 100 & 100 \\
\hline
\end{tabular}

BDA: meio de cultura.

As etapas de inoculação que incluíram os fungos, independentemente da presença de danos mecânicos, tenderam a afetar negativamente a qualidade das sementes. Quando comparados entre si, Aspergillus sp. e F. moniliforme geraram maiores prejuízos do que Penicillium sp. Resultados similares, associando a presença de fungos com a depressão da qualidade fisiológica das sementes, foram relatados por Dhingra et al. (1980), Filgueiras (1981) e LuCCA FiLHO (1985). Wu e CHENG (1990), trabalhando com fungos associados às sementes de sorgo, entre os quais F. moniliforme, verificaram a existência de relações entre os patógenos e os prejuízos no desempenho das sementes. 
Quadro 3. Densidade ponderada de infecção (\%) em sementes de milho, submetidas a diferentes tipos de danificação mecânica e de inoculação

\begin{tabular}{|c|c|c|c|c|c|c|}
\hline \multirow{2}{*}{ Experimento } & \multirow{2}{*}{ Etapa de inoculação } & \multirow{2}{*}{ Região } & \multicolumn{4}{|c|}{ Danificação } \\
\hline & & & $\mathrm{D}_{0}$ & $\mathrm{D}_{1}$ & $\mathrm{D}_{2}$ & $\mathrm{D}_{3}$ \\
\hline \multirow{3}{*}{1} & Assepsia & $\mathrm{R}_{1}$ & $56 \mathrm{Cc}$ & $64 \mathrm{Ab}$ & $63 \mathrm{Bc}$ & 53Dc \\
\hline & Assepsia + BDA & $\mathrm{R}_{2}$ & $60 \mathrm{Cb}$ & 51Dc & 88Аa & $62 \mathrm{Bb}$ \\
\hline & Assepsia + BDA + Aspergillus sp. & $\mathrm{R}_{3}$ & $76 \mathrm{Ba}$ & $65 \mathrm{Da}$ & $69 \mathrm{Cb}$ & $83 \mathrm{Aa}$ \\
\hline \multirow{3}{*}{2} & Assepsia & $\mathrm{R}_{1}$ & $53 \mathrm{Dc}$ & $66 \mathrm{Bc}$ & $67 \mathrm{Ab}$ & $61 \mathrm{Cc}$ \\
\hline & Assepsia + BDA & $\mathrm{R}_{2}$ & $56 \mathrm{Cb}$ & $81 \mathrm{Ba}$ & $81 \mathrm{Ba}$ & $88 \mathrm{Aa}$ \\
\hline & Assepsia + BDA + Penicillium sp. & $\mathrm{R}_{3}$ & 86Aa & $71 \mathrm{Cb}$ & $81 \mathrm{Ba}$ & $81 \mathrm{Bb}$ \\
\hline \multirow{3}{*}{3} & Assepsia & $\mathrm{R}_{1}$ & $51 \mathrm{Bc}$ & $76 \mathrm{Aa}$ & $22 \mathrm{Cc}$ & 17Dc \\
\hline & Assepsia + BDA & $\mathrm{R}_{2}$ & $53 \mathrm{Bb}$ & 20Dc & $63 \mathrm{Aa}$ & $38 \mathrm{Cb}$ \\
\hline & Assepsia + BDA + Fusarium moniliforme & $\mathrm{R}_{3}$ & $65 \mathrm{Aa}$ & $25 \mathrm{Db}$ & $48 \mathrm{Cb}$ & $58 \mathrm{Ba}$ \\
\hline
\end{tabular}

BDA: meio de cultura. Para cada experimento, médias seguidas por mesma letra maiúscula na linha e por mesma letra minúscula na coluna não difere estatisticamente, entre si, pelo teste Tukey $(\mathrm{P}>0,05)$.

Quadro 4. Germinação (\%) de sementes de milho, submetidas a diferentes tipos de danificação mecânica e de inoculação

\begin{tabular}{|c|c|c|c|c|c|}
\hline \multirow{2}{*}{ Experimento } & \multirow{2}{*}{ Etapa de inoculação } & \multicolumn{4}{|c|}{ Danificação } \\
\hline & & $\mathrm{D}_{0}$ & $\mathrm{D}_{1}$ & $\mathrm{D}_{2}$ & $\mathrm{D}_{3}$ \\
\hline \multirow{3}{*}{1} & Assepsia & 98Bab & 99Aа & $96 \mathrm{Ba}$ & $90 \mathrm{Ca}$ \\
\hline & Assepsia + BDA & 99Aа & 99Aа & $79 \mathrm{Cb}$ & $86 \mathrm{Ba}$ \\
\hline & Assepsia + BDA + Aspergillus sp. & $97 \mathrm{Ab}$ & $96 \mathrm{Ab}$ & $65 \mathrm{Bc}$ & $46 \mathrm{Cb}$ \\
\hline \multirow{3}{*}{2} & Assepsia & $98 \mathrm{Aa}$ & 99Aa & $95 \mathrm{Ba}$ & $91 \mathrm{Ca}$ \\
\hline & Assepsia + BDA & 98Aa & $96 \mathrm{Ab}$ & $83 \mathrm{Bb}$ & $76 \mathrm{Cb}$ \\
\hline & Assepsia + BDA + Penicillium sp. & 98Aa & 98Aa & $86 \mathrm{Bb}$ & $72 \mathrm{Cb}$ \\
\hline \multirow{3}{*}{3} & Assepsia & 99Aа & $98 \mathrm{Aba}$ & $97 \mathrm{Ba}$ & $88 \mathrm{Ca}$ \\
\hline & Assepsia + BDA & $97 \mathrm{Ab}$ & 98Aa & $76 \mathrm{Cb}$ & $85 \mathrm{Bb}$ \\
\hline & Assepsia + BDA + Fusarium moniliforme & $98 \mathrm{Ab}$ & $86 \mathrm{Bb}$ & $35 \mathrm{Dc}$ & $86 C \mathrm{c}$ \\
\hline
\end{tabular}

BDA: meio de cultura. Para cada experimento, médias seguidas por mesma letra maiúscula na linha e por mesma letra minúscula na coluna não difere estatisticamente, entre si, pelo teste Tukey $(P>0,05)$.

Quadro 5. Plântulas emersas (\%) obtidas no teste de frio de sementes de milho, submetidas a diferentes tipos de danificação mecânica e de inoculação

\begin{tabular}{|c|c|c|c|c|c|}
\hline \multirow{2}{*}{ Experimento } & \multirow{2}{*}{ Etapa de Inoculação } & \multicolumn{4}{|c|}{ Danificação } \\
\hline & & $\mathrm{D}_{0}$ & $\mathrm{D}_{1}$ & $\mathrm{D}_{2}$ & $\mathrm{D}_{3}$ \\
\hline \multirow{3}{*}{1} & Assepsia & $95 \mathrm{Aa}$ & $71 \mathrm{Bc}$ & $71 \mathrm{Ba}$ & $68 \mathrm{Bb}$ \\
\hline & Assepsia + BDA & $95 \mathrm{Aa}$ & $90 \mathrm{Ba}$ & $67 \mathrm{Db}$ & $76 \mathrm{Ca}$ \\
\hline & Assepsia + BDA + Aspergillus sp. & $92 \mathrm{Ab}$ & $87 \mathrm{Bb}$ & $55 \mathrm{Cc}$ & $56 \mathrm{Cc}$ \\
\hline \multirow{3}{*}{2} & Assepsia & 98Aa & $77 \mathrm{Bc}$ & $76 \mathrm{Ba}$ & $71 \mathrm{Cb}$ \\
\hline & Assepsia + BDA & $97 \mathrm{Aa}$ & $86 \mathrm{Bb}$ & $66 \mathrm{Db}$ & $74 \mathrm{Ca}$ \\
\hline & Assepsia + BDA + Penicillium sp. & $93 \mathrm{Bb}$ & 97Aa & $56 \mathrm{Dc}$ & $77 \mathrm{Ca}$ \\
\hline \multirow{3}{*}{3} & Assepsia & $99 \mathrm{Aa}$ & $77 \mathrm{Bc}$ & $77 \mathrm{Ba}$ & $78 \mathrm{Ba}$ \\
\hline & Assepsia + BDA & $97 \mathrm{Ab}$ & $88 \mathrm{Bb}$ & $70 \mathrm{Db}$ & $75 \mathrm{Ca}$ \\
\hline & Assepsia + BDA + Fusarium moniliforme & 95Ac & 92Ba & 28Dc & $67 \mathrm{Cb}$ \\
\hline
\end{tabular}

BDA: meio de cultura. Para cada experimento, médias seguidas por mesma letra maiúscula na linha e minúscula na coluna, não difere estatisticamente, entre si, pelo teste Tukey $(P>0,05)$. 
Quadro 6. Comprimento de plântulas $(\mathrm{mm})$, provenientes de sementes de milho, submetidas a diferentes tipos de danificação mecânica e de inoculação

\begin{tabular}{|c|c|c|c|c|c|}
\hline \multirow{2}{*}{ Experimento } & \multirow{2}{*}{ Etapa de Inoculação } & \multicolumn{4}{|c|}{ Danificação } \\
\hline & & $\mathrm{D}_{0}$ & $\mathrm{D}_{1}$ & $\mathrm{D}_{2}$ & $\mathrm{D}_{3}$ \\
\hline \multirow{3}{*}{1} & Assepsia & $46 \mathrm{Aa}$ & $45 \mathrm{Aa}$ & $21 \mathrm{Ba}$ & $18 \mathrm{Ca}$ \\
\hline & Assepsia + BDA & $45 \mathrm{Ab}$ & $45 \mathrm{Aa}$ & $7 \mathrm{Bb}$ & $5 \mathrm{Cc}$ \\
\hline & Assepsia + BDA + Aspergillus sp. & $43 \mathrm{Ab}$ & $32 \mathrm{Bb}$ & $9 \mathrm{Cb}$ & $7 \mathrm{Db}$ \\
\hline \multirow{3}{*}{2} & Assepsia & 47Aa & $51 \mathrm{Aa}$ & $25 \mathrm{Ba}$ & $22 \mathrm{Ba}$ \\
\hline & Assepsia + BDA & $47 \mathrm{Aa}$ & $46 \mathrm{Ab}$ & $7 \mathrm{Bc}$ & $8 \mathrm{Bb}$ \\
\hline & Assepsia + BDA + Penicillium sp. & $39 \mathrm{Ab}$ & $26 \mathrm{Bc}$ & $14 \mathrm{Cb}$ & $7 \mathrm{Db}$ \\
\hline \multirow{3}{*}{3} & Assepsia & $49 \mathrm{Aa}$ & $48 \mathrm{Aa}$ & $27 \mathrm{Ba}$ & $28 \mathrm{Ba}$ \\
\hline & Assepsia + BDA & $46 \mathrm{Bb}$ & $48 \mathrm{Aa}$ & $8 \mathrm{Cc}$ & $9 \mathrm{Cb}$ \\
\hline & Assepsia + BDA + Fusarium moniliforme & $45 \mathrm{Ab}$ & $17 \mathrm{Bb}$ & $14 \mathrm{Cb}$ & $4 \mathrm{Dc}$ \\
\hline
\end{tabular}

BDA: meio de cultura. Para cada experimento, médias seguidas por mesma letra maiúscula na linha e minúscula na coluna, não difere estatisticamente, entre si, pelo teste Tukey $(\mathrm{P}>0,05)$.

Quadro 7. Emergência de plântulas (\%) provenientes de sementes de milho, submetidas a diferentes tipos de danificação mecânica e de inoculação

\begin{tabular}{clccrr}
\hline \multirow{2}{*}{ Experimento } & \multirow{4}{c}{ Danificação } \\
\cline { 3 - 6 } & Etapa de Inoculação & $\mathrm{D}_{0}$ & $\mathrm{D}_{1}$ & $\mathrm{D}_{2}$ & $\mathrm{D}_{3}$ \\
\hline \multirow{3}{*}{1} & Assepsia & $97 \mathrm{Aa}$ & $96 \mathrm{Aa}$ & $71 \mathrm{Bb}$ & $70 \mathrm{Bb}$ \\
& Assepsia + BDA & $97 \mathrm{Aa}$ & $94 \mathrm{Bb}$ & $76 \mathrm{Ca}$ & $77 \mathrm{Ca}$ \\
& Assepsia + BDA + Aspergillus sp. & $97 \mathrm{Aa}$ & $68 \mathrm{BCc}$ & $65 \mathrm{Cc}$ & $70 \mathrm{Bb}$ \\
\multirow{2}{*}{2} & Assepsia & $98 \mathrm{Ba}$ & $99 \mathrm{Aa}$ & $76 \mathrm{Ca}$ & $71 \mathrm{Db}$ \\
& Assepsia + BDA & $97 \mathrm{Aab}$ & $97 \mathrm{Ab}$ & $77 \mathrm{Ba}$ & $74 \mathrm{Bb}$ \\
& Assepsia + BDA + Penicillium sp. & $96 \mathrm{Ab}$ & $96 \mathrm{Ab}$ & $65 \mathrm{Cb}$ & $88 \mathrm{Ba}$ \\
\multirow{2}{*}{3} & Assepsia & $100 \mathrm{Aa}$ & $98 \mathrm{Ba}$ & $77 \mathrm{Ca}$ & $77 \mathrm{Ca}$ \\
& Assepsia + BDA & $97 \mathrm{Ab}$ & $97 \mathrm{Aa}$ & $77 \mathrm{Ba}$ & $75 \mathrm{Ba}$ \\
& Assepsia + BDA + Fusarium moniliforme & $97 \mathrm{Ab}$ & $94 \mathrm{Bb}$ & $34 \mathrm{Db}$ & $73 \mathrm{Ca}$ \\
\hline
\end{tabular}

BDA: meio de cultura. Para cada experimento, médias seguidas por mesma letra maiúscula na linha e minúscula na coluna, não difere estatisticamente, entre si, pelo teste Tukey $(\mathrm{P}>0,05)$.

Da mesma forma, TANAKA e CORREA (1981), em sementes de feijão infectadas com Aspergillus spp. e Penicillium spp. previamente ao armazenamento, observaram influências da ação dos fungos na germinação e na emergência das plântulas. Em milho, LÓPES e CHRISTENSEN (1967) evidenciaram redução na germinação decorrente da incidência de Aspergillus flavus inoculado nas sementes.

Os prejuízos, advindos das associações entre as danificações e os fungos inoculados, foram mais freqüentes quando reunidos os danos próximos ao embrião $\left(\mathrm{D}_{2}\right.$ e $\left.\mathrm{D}_{3}\right)$ com os fungos Aspergillus sp. e $F$. moniliforme. Nesses casos, a região danificada tendeu a se constituir em local facilitador para a colonização dos fungos. Similarmente, Delouche e Andrews (1964), Popinigis (1977) e Marcos FiLho (1986) revela- ram que as injúrias são prejudiciais ao desempenho e, nesse sentido, Soave e Wetzel (1987) observaram que o efeito gerado ganha importância em virtude de propiciar abertura de canais para a entrada de microrganismos.

Em sementes de milho, TATUM e ZUBER (1943) observaram que a ação negativa do dano depende de sua severidade que, quando ampliada, facilita a colonização do fungo; da mesma forma, Meyers (1924), utilizando sementes de milho danificadas e portadoras de Penicillium sp., verificou reduções nas populações de plantas afetando a produção durante dois anos de estudo. Adicionalmente, Moore (1974) ressaltou que, em comparação com a injúria do tipo "quebramento", o "amassamento" eleva os efeitos latentes em virtude de, aumentando o contato de tecidos 
lesionados com os intactos, estimular a formação de um centro de infecção utilizado por fungos de armazenamento como local de estabelecimento na semente.

\section{CONCLUSÕES}

1. As danificações mecânicas em sementes de milho, particularmente quando Aspergillus sp. e F. moniliforme acham-se presentes, promovem prejuízos qualitativos fisiológicos progressivos à medida que se aproximam do embrião.

2. Quando comparadas entre si, as interferências negativas de Aspergillus sp. e de F. moniliforme são mais evidentes do que as de Penicilium sp.

\section{REFERÊNCIAS BIBLIOGRÁFICAS}

BEWLEY, J.D.; BLACK, M. Seeds: physiology of development and germination. New York: Plenum Press, 1985. 367p.

BRASIL. Ministério da Agricultura, do Abastecimento e da Reforma Agrária. Departamento Nacional de Produção Vegetal - Divisão de Sementes e Mudas. Regras para Análise de Sementes. Brasília, 1992. 365p.

CARVALHO, N.M. ; NAKAGAWA, J. Sementes: ciência, tecnologia e produção. Campinas: Fundação CARGILL, 1983. 429p.

COPELAND, L.O. How seed damage affects germination. Crops and Soils Magazine, Madison, v.24, n.9, p. 9-12, 1972.

CRAIG, W.F. Production of hybrid corn seed. In: SPRAGUE, G.F. (Ed.). Corn and corn improvement. Washington: American Society of Agronomy, 1977. p.671-719.

DELOUCHE, J.C.; ANDREWS, C.H. Tests show how injury lowers quality of seed. Seed World, Chicago, v. 95, n. 6, p.10, 1964.

DHINGRA, O.D.; MUCHOVEJ, J.J.; CRUZ FILHO, J. Tratamento de sementes: controle de patógenos. Viçosa: Imprensa Universitária, 1980. 121p.

FAGUNDES, S.R.F. Como predizer a qualidade de um lote de sementes. Sementes, Brasília, v. 10, n. 6, p. 14-18, 1985.

FILGUEIRAS, T.S. Seed vigor and productivity. Pesquisa Agropecuária Brasileira, Brasília, v.16, n.6, p.851-854, 1981.

FINCH, E.O.; COELHO, A.M.; BRANDINI, A. Colheita de milho. Informe Agropecuário, Belo Horizonte, v. 6, n. 72, p. 61-66, 1980.

GONÇALVES, C.A.R. Efeitos de métodos de colheita e debulha de sementes sobre a germinação e produção de milho (Zea mays L.). 1981. 122f. Tese (Mestrado) - Escola Superior de Agricultura "Luiz de Queiróz", Universidade de São Paulo, Piracicaba.
LÓPEZ, LCHRISTENSEN, C.M. Effect of moisture content and temperature on invasion of stored corn by Aspergillus flavus. Phytopathology, St. Paul, v.57, p.588-590, 1967.

LUCCA FILHO, O.A.. Importância da sanidade na produção de sementes de alta qualidade. Revista Brasileira de Sementes, Brasília, v.7, n.1, p. 113-123, 1985.

KOELHER, B. Pathologie significance of seed coat injury in dent corn. Phytopathology, St. Paul, v.25, p.24, 1935.

KRZYZANOWSKI, F.C.; FRANÇA NETO, J.B.; HENNING, A.A. Relato dos testes de vigor disponíveis para grandes culturas. In: Informativo ABRATES, Brasília, v.1, n.2, p.15-50, 1991.

MACHADO, J.C.; MARTINS, L.P.S. Informativo ABRATES, Brasília, vol.9, n.1-2, 1999. (Resumo, 165)

MARCOS FILHO, J. Germinação de sementes. In: SEMANA DE ATUALIZAÇÃO EM PRODUÇÃO DE SEMENTES, 1., 1986, Piracicaba. Campinas: Fundação Cargill, 1986. p.11-39.

MARCOS FILHO, J.; CICERO, S.M.; SILVA, W.R. Avaliação da qualidade das sementes. Piracicaba: FEALQ, 1987. 230p.

MCKEEN, W.E.; MACDONALD, B. Leakage, infection and emergence of injured corn seed. Phytopathology, St. Paul, v.66, p.928-930, 1976

MEYERS, M.T. The influence of broken pericarp on the germination and yield of corn. Journal of the American Society of Agronomy, Madison, v.16, n. 8, p. 540-550, 1924.

MOORE, R.P. Effects of mechanical injuries on viability. In: ROBERTS, E.H. (Ed.). Viability of seeds. London: Chapman \& Hall Syracuse University Press, 1974. p.94-113.

NAKAGAWA, J. Testes de vigor baseados na avaliação das plântulas. In: Vieira, R.D.; Carvalho, N.M. (Eds.). Testes de vigor em sementes. Jaboticabal: FUNEP, 1994, p.59-65.

POLLOCK, B.M.; ROOS, E.E. Seeds and seedling vigor. In: KOZLOWSKY, T.T. (Ed). Seed Biology. New York: Academic Press, 1972, v.1, p.313-387.

POPINIGIS, F. Fisiologia da semente. Brasília: Ministério da Agricultura AGIPLAN, 1977. 289p.

SATO, O. Efeitos da seleção de espigas e da debulha na qualidade física e fisiológica das sementes de milho (Zea mays L.). 1974. 49f. Tese (Mestrado) - Escola Superior de Agricultura "Luiz de Queiroz", Universidade de São Paulo, Piracicaba.

SILVA, W.R.; CHAMMA, H.M.C.P.; NOVEMBRE, A.D.L.C.; MORAES, M.H.D. Avaliação do desempenho de sementes de milho submetidas à remoção parcial do endosperma e do pericarpo. Scientia Agricola, Piracicaba, v.51, n.1, p.138-152, 1994.

SOAVE, J.; WETZEL, M.V.S. (Eds.) Patologia de sementes. Campinas: Fundação Cargill, 1987. 480p.

TANAKA, M.A.S.; CORRÊA, M.U. Influência de Aspergillus e Penicillium no armazenamento de sementes de feijão (Phaseolus vulgaris L.). Fitopatologia Brasileira, Brasília, v. 6, n. 3, p. 451-456, 1981. 
TATUM, L.A.; ZUBER, M.S. Germination of maize under adverse conditions. Journal of the American Society of Agronomy, Madison, v. 35, n.1, p. 48-49, 1943.

WORTMAN, L. S.; RINKE, E. H. Seed corn injury at various stages of processing and its effect upon cold test performance. Agronomy Journal, Madison, v.43, n.7, p.229-305, 1951.
WU, W-S.; CHENG, K-C. Relationships between seed health, seed vigour and the performance of sorghum in the field. Seed Science E Technology, Zurich, v. 18, p. 713-719, 1990.

ZONTA, E.P.; MACHADO, A.A. Sistema de análise estatística para microcomputadores. Pelotas: SANEST, 1984. 